\title{
Perspectives on chronic cough in Korea
}

\section{Ji-Hyang Lee, Woo-Jung Song}

Department of Allergy and Clinical Immunology, Airway Sensation and Cough Research Laboratory, Asan Medical Center, University of Ulsan College of Medicine, Seoul, Korea

Contributions: (I) Conception and design: WJ Song; (II) Administrative support: None; (III) Provision of study materials or patients: None; (IV) Collection and assembly of data: All authors; (V) Data analysis and interpretation: All authors; (VI) Manuscript writing: All authors; (VII) Final approval of manuscript: All authors.

Correspondence to: Woo-Jung Song, MD, PhD. Department of Allergy and Clinical Immunology, Airway Sensation and Cough Research Laboratory, Asan Medical Center, University of Ulsan College of Medicine, 88, Olympic-ro 43-gil, Songpa-gu, Seoul 05505, Korea.

Email: swj0126@amc.seoul.kr.

\begin{abstract}
Chronic cough is a common condition, and generally affects about $3 \%$ of Korean adults with a significant influence on quality of life (QoL). Despite continued clinical and academic efforts, there are unmet needs for chronic cough prevention and management in Korea. Epidemiologically, there are two major challenges: an aging population and air pollution. Korea is one of the most rapidly aging countries, and the relative proportion of elderly to younger people is expected to double within the next two decades. Air pollution is a major concern, but there is very limited evidence on the effects of air pollutant on cough in Korean patients. Clinically, upper and lower airway diseases, such as rhinitis/rhinosinusitis and cough variant asthma/eosinophilic bronchitis, are reported to account for about $75 \%$ of chronic cough in Korean adults, which formed the basis in formulating clinical practice guidelines. However, further studies are warranted to resolve clinical uncertainty, particularly for the evaluation and treatment of upper airway conditions in chronic cough. The prevalence of gastroesophageal reflux disease (GERD) is increasing, thus its relevance to cough among Koreans may warrant re-evaluation. Infection-associated chronic cough, such as tuberculosis, is another continuing concern. The proportion of chronic refractory or unexplained cough is assumed to be 10-20\% among patients visiting referral clinics for chronic cough. This review presents our perspectives on current epidemiological and clinical issues of chronic cough in Korea, and addresses major knowledge gaps and future research priorities.
\end{abstract}

Keywords: Chronic cough; Korea; epidemiology; etiology; review

Submitted Mar 28, 2020. Accepted for publication Aug 11, 2020.

doi: $10.21037 /$ jtd-2020-icc-004

View this article at: http://dx.doi.org/10.21037/jtd-2020-icc-004

\section{Introduction}

Cough is a physiological reflex to protect the lower airways against aspiration and irritation, but it is also one of the most common medical problems in many parts of the world (1). In a study in Asian-Pacific countries, cough was the main reason for medical visits among patients with upper and lower respiratory diseases (2). In particular, chronic cough, usually defined as lasting eight or more weeks, has received much national and international attention, as it frequently persists for years, has significant physical, social, and psychological consequences, and is often refractory to treatments (3-11).

Chronic cough is a globally prevalent condition, but its epidemiological and clinical considerations may be locally different (12-14). In Korea, since the first cough clinic was established in the 1990s, chronic cough has been one of the major research interests of allergy and respiratory specialists $(9,15)$. Upper and lower airway diseases, such as rhinitis, sinusitis, asthma, or eosinophilic bronchitis, were found to be frequent in Korean adults with chronic cough $(16,17)$, which formed the basis in setting priorities and formulating 


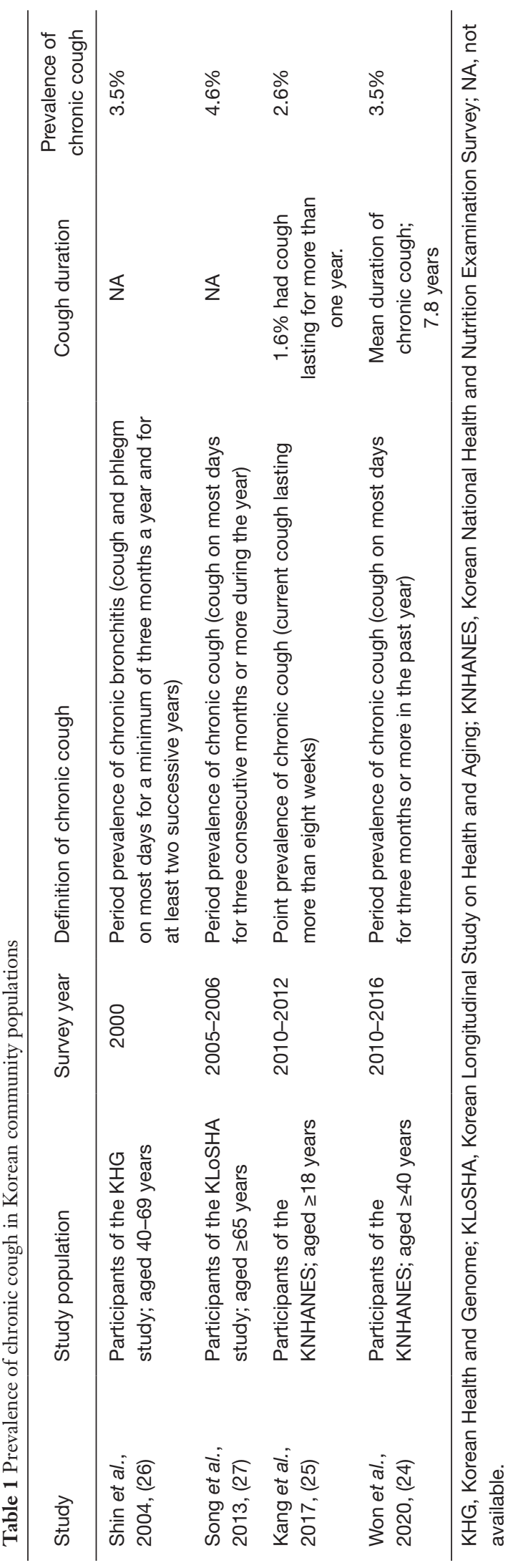

recent clinical practice guidelines in Korea (9). Despite these efforts, there are unmet clinical needs of patients in the community, particularly regarding diagnosis and treatment (18).

This review presents our perspectives on current epidemiological and clinical issues of chronic cough in Korea. Based on a recent paradigm shift and progress in mechanistic and clinical studies for cough (19-21), this review also describes major knowledge gaps and future research priorities for chronic cough in Korea.

\section{Epidemiology of chronic cough: global and local perspectives}

The global prevalence of chronic cough is estimated as approximately $10 \%$ in adults, but the regional prevalence in Asian countries is lower (4.4\%) than that in Europe (12.7\%) or America (11.0\%) (12). Reasons for regional differences are not clear. However, host factors such as allergies, obesity, or gastroesophageal reflux may underlie the regional heterogeneity, because these conditions are less prevalent in Asian than in western populations (13). There is no comprehensive study on the roles of genetic factors in the epidemiology of chronic cough in adult populations. Only a few studies reported genetic polymorphisms in transient receptor potential vanilloid-1 (TRPV1) or neurokinin-2 receptor in relation to specific phenotypes of cough $(22,23)$.

The Korean National Health and Nutrition Examination Survey (KNHANES) has enabled estimation of the nationwide prevalence of chronic cough in Korean adults (https://knhanes.cdc.go.kr/knhanes/eng/index.do). It is annually assessed using a structured questionnaire about a period prevalence ("Have you had a cough on most days for three months or more during the past year?"). The period prevalence of chronic cough in the KNHANES 2010-2016 has been estimated as $3.48 \% \pm 0.17 \%$ among adults aged 40 years or older (24). Point prevalence (having current cough for two months or longer at the time of survey) is a preferred measure for studying cough epidemiology, as it is less subject to recall bias; however, it was only assessed for a limited period of the KNHANES surveys [2010-2012] and was noted as $2.6 \% \pm 0.2 \%$ (25). Similarly, in two different regional community-based studies of middle-aged or older adult populations, period prevalences were approximately 4-5\% (26,27) (Table 1).

Notably, chronic cough is more prevalent among older adults in many countries including Korea (28). It is 
speculated that more frequent comorbidities in older adults may underlie the age-related prevalence patterns. Lung parenchymal diseases or structural changes may possibly be important in chronic cough among older adults; unlike in younger adults, abnormal chest $\mathrm{X}$-ray findings were significantly more frequent in elderly patients (aged 65 or older) with chronic cough than in those without cough (45.5\% vs. 25.1\%; $\mathrm{P}<0.001$ ), and one outstanding finding was inactive tuberculosis $(27.3 \%$ vs. $14.2 \%$; $\mathrm{P}<0.001)(28)$. However, in multivariate analyses of the KNHANES population dataset, the associations between chronic cough and old age were independent of comorbid conditions including asthma, chronic rhinosinusitis, or chest X-ray abnormalities (25), suggesting the need for further investigation of the age-related increase in prevalence. According to the World Population Prospects 2017 report, population aging is a globally emerging issue, but it is expected to be more dramatic in some Asia-Pacific countries like Korea, Japan, Singapore, and Thailand (29). Elderly people comprised $14.9 \%$ of the total Korean population in 2019 , but this may increase to $46.5 \%$ (median age of 62.2 years old) in 2067 (http://kosis.kr/index/index.do). Due to frequent comorbidities and potential side effects from medications, chronic cough in older adults is more challenging to manage than that in younger patients (30). Therefore, prevention and management strategies for chronic cough problems in older adults should be developed further.

Given the high prevalence and impact on quality of life (QoL), the disease burden of chronic cough is expected to be substantial. However, it has not been formally estimated (11). In the recent KNHANES 2010-2016 analyses, chronic cough was significantly associated with lower EuroQoL 5-dimension (EQ-5D) index scores in Korean adults, independently of confounding factors (24). The mean difference in the EQ-5D index score between subjects with and without chronic cough exceeded the minimally important difference $(0.79 \pm 0.01$ vs. $0.86 \pm 0.00 ; \mathrm{P}<0.001)$; notably, the score difference was more remarkable in elderly women than in men or younger women, indicating that elderly women are the most susceptible demographic group warranting active interventions for chronic cough (24). Moreover, in a recent internet-based questionnaire survey of 15,000 adults in the UK, a mean EQ-5D index score was 0.71 in patients with chronic cough, which was significantly lower than 0.83 in healthy controls (31), confirming the impact of chronic cough.

\section{Air pollution and chronic cough}

Cough is a defensive reflex; thus, environmental factors should affect the epidemiology and clinical characteristics of chronic cough. In particular, air pollution is a major concern due to its considerable impact on respiratory health including cough (32). Unlike western countries, the annual mean concentrations of fine particulate matter with a diameter of $2.5 \mu \mathrm{g} / \mathrm{m}^{3}$ or less $\left(\mathrm{PM}_{2.5}\right)$, an indicator for ambient air pollution, are high $\left(\geq 25 \mu \mathrm{g} / \mathrm{m}^{3}\right)$ in many Asian countries (32). Ironically, the prevalence of chronic cough in Asia is less than half of that in Europe or America (12). This discrepancy leads to speculation that air pollution is not a major determinant for the prevalence of chronic cough, although air pollutants are apparent triggers for provoking cough (33). Given acute effects of pollutant exposure on cough, the true impact of air pollution on chronic cough warrants longitudinal investigation, particularly for its long-term remnant effects (33). Meanwhile, recent animal experiments suggested some detail how air pollutant exposure may induce cough. In a recent study by Fang and colleagues, the experimental exposure to heavy traffic was significantly associated with cough reflex hypersensitivity and eosinophilic airway inflammation in guinea pigs (34). Another guinea pig model demonstrated that intranasal administration of $\mathrm{PM}_{2.5}$ induced cough reflex hypersensitivity and up-regulated TRPV1 expression in airways and dorsal vagal complex (35).

However, so far, there is a very limited number of studies on the impact of air pollution on chronic cough in Korea. In a panel study during Asian sand dust seasons, high levels of $\mathrm{PM}_{10}, \mathrm{NO}_{2}$, or ozone were related to weather-related cough in Korean patients with chronic obstructive pulmonary disease (COPD), as compared to control subjects without respiratory diseases (36). In a cross-sectional study of adult residents living near industrial complexes in Korea, cough was significantly more prevalent among the residents living near industrial complex cities, as compared to residents outside the influence of industrial complexes [odds ratio (OR), 1.18; $95 \%$ confidence interval (95\% CI), 1.06-1.31] (37).

\section{Clinical epidemiology of Korean patients}

\section{Demographics and cough sensitivity}

The predominance of older women is a relatively wellknown finding in chronic cough (4). A recent worldwide survey confirmed this observation, in a study which 
consisted of 10,032 chronic cough patients recruited from 11 cough clinics in six countries (China, Holland, Korea, Sweden, UK, and the US) (38). Two-thirds of the participants were women and the most common age for clinical presentation was 60-69 years (mean age: 55 years); the demographic profile was mostly uniform across centers and countries, except for China (38). The female predominance is presumably attributed to sex differences in the following factors, including cough reflex sensitivity, central processing of cough, and impact of cough on QoL (or the complications with coughing) $(24,38,39)$. It has been repeatedly found that women have a heightened cough sensitivity to tussigen inhalation than men (40-44). Also, in a functional brain imaging study, women showed greater activation of the somatosensory cortex than men, even with lower dose capsaicin inhalation (38). Estrogen hormone has been suggested as one of the mechanistic links to cough reflex sensitivity, as it may enhance the function of TRPV1 $(45,46)$. However, estrogen hypothesis may not explain a large proportion of post-menopausal women among patients with chronic refractory or explained cough. Meanwhile, a reason for the difference in Chinese patients (roughly equal sex distribution and middle-aged predominance) is still unclear (14). There is no evidence for an ethnic difference in cough sensitivity (47).

Among Korean patients, the older female predominance appears to be more evident in unexplained or refractory chronic cough. In a recent multi-center study, the percentage of women was significantly higher in patients with unexplained chronic cough than in those newly referred with chronic cough $(85.5 \%$ vs. $65.9 \% ; \mathrm{P}=0.002)$ (48). It utilized the Cough Hypersensitivity Questionnaire (CHQ) to assess a symptom profile related to cough hypersensitivity, and found that patients with unexplained chronic cough had significantly more cough triggers and laryngeal sensations than those with chronic cough $(6.9 \pm 2.6$ vs. $5.0 \pm 2.8 ; \mathrm{P}<0.001$; and $4.4 \pm 1.5$ vs. $3.9 \pm 1.9 ; \mathrm{P}=0.049$, respectively), but suggested that cough hypersensitivity is not exclusive to refractory cough but that it is common to overall chronic cough patients. In addition, the CHQ score was significantly higher in women than in men $(8.9 \pm 3.7$ vs. $8.0 \pm 3.4$; $\mathrm{P}=0.013$ ) (48), also suggesting interactions between sex and cough hypersensitivity.

\section{Rhinitis and rbinosinusitis: uncertainties}

Upper airway symptoms or diseases are reportedly found in about half of Korean adult patients with chronic cough, although their causal relationships are controversial (16). According to the specialist clinic data in Seoul, about 50\% of the adult patients had nasal symptoms (rhinorrhea or nasal obstruction) or positive nasal endoscopic findings (defined by the presence of nasal polyps, mucopurulent discharge, or edema in the middle meatus) (44).

Specific diagnoses for upper airway conditions in these patients were not described in detail. Likewise, in a survey of Korean allergists in 2012, sinus X-ray was the second most common diagnostic tool in the daily practice of chronic cough management $(70.1 \%)$, which was next only to chest X-rays (87\%) (17). Rhinoscopy (22.1\%) and laryngoscopy $(12 \%)$ were also considered as a part of routine investigation in some clinics (17).

In this context, a short-term empirical trial with H1receptor antagonists (H1RAs) (preferably first-generation agents) is strongly recommended for Korean adults with chronic cough, even in the absence of nasal symptoms or signs (Figure 1) (9). This recommendation is supported by randomized clinical trials (RCTs), and also by low costs, ease of accessibility, and known, expectable adverse reactions of H1RAs (9). However, there are controversies and uncertainties regarding the true benefits of H1RA treatment in chronic cough. First, the recommendation was based on a very low level of evidence. There were only three clinical trials with older generation H1RAs (diphenhydramine, loratadine, or oxatomide), which did not utilize validated cough measurement tools (9). Second, older generation H1RAs may exert anticholinergic side effects, such as sleep disturbance, inattention, disorganized speech, or alterations in consciousness, which can be more harmful in older adults (49). To our knowledge, there is no high quality evidence to confirm benefits of newer generation H1RAs using validated cough endpoints. Placebo-controlled trials are warranted to confirm this, as cough is frequently selflimiting and prone to placebo effects (50).

In the literature, there is a controversy regarding the clinical impact of assessing and controlling nasal diseases in chronic cough, even though they frequently overlap. Mechanistically, nasal inflammation does not directly trigger cough reflex via the vagus nerves, although it may sensitize the cough reflex through activation of the trigeminal nerves (51). In an observational study of 108 subjects with purulent postnasal drip, only 9 (8\%) complained of cough in the absence of other pathology (52). In a prospective study of chronic cough patients $(n=36)$, sinus imaging was not useful in determining the cause of cough (53). 


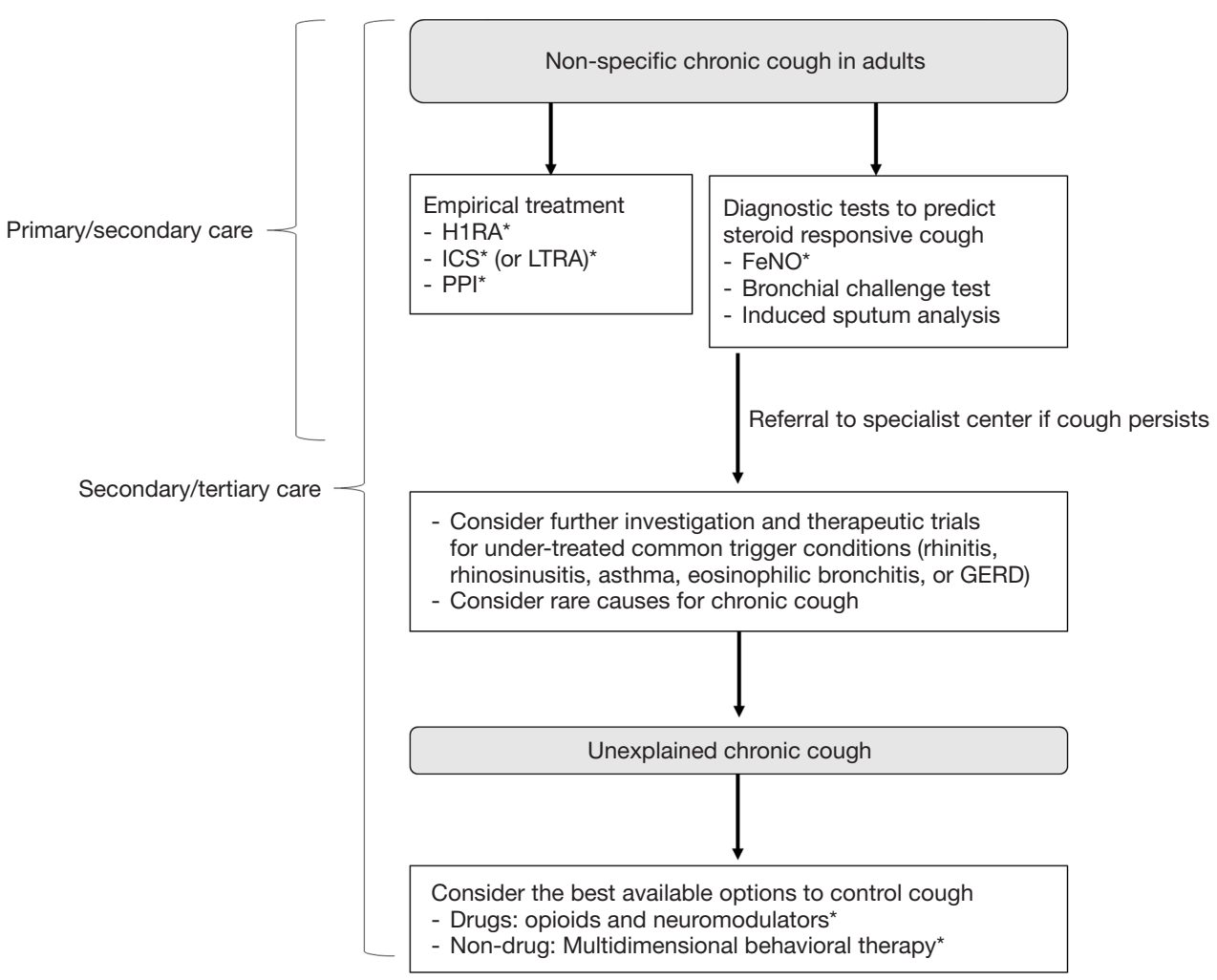

Figure 1 Management of non-specific chronic cough in Korean adults (age $\geq 15$ years), recommended in the 2018 KAAACI Evidence-Based Clinical Practice Guidelines for Chronic Cough in Korea [reproduced from Song et al., Allergy Asthma Immunol Res 2018;10:591-613, with permission of the journal] (9). Decision for empirical treatment and diagnostic tests may depend on clinical and instrument settings. Patients with chronic cough unresponsive to empirical trials or specific treatment should be referred to specialist centers for further diagnostic tests and therapeutic trials. If cough is still unexplained, pharmacological and non-pharmacological treatment options are considered to control cough. Asterisk $\left(^{*}\right)$ indicates the drug (or test) of interest in the present guidelines. KAAACI, Korean Academy of Asthma, Allergy and Clinical Immunology; H1RA, histamine-1 receptor antagonist; ICS, inhaled corticosteroid; LTRA, leukotriene receptor antagonist; PPI, proton-pump inhibitor; GERD, gastroesophageal reflux disease; FeNO, fractional exhaled nitric oxide.

\section{Cough variant asthma and eosinophilic bronchitis: diagnostic issues}

Cough variant asthma and eosinophilic bronchitis are common type 2 airway inflammatory conditions presenting with chronic cough, accounting for about $25-50 \%$ of Korean adult patients (16). Notably, these are particular conditions in which objective diagnostic tests, such as bronchial challenge or induced sputum testing, are preferred to empiric treatment during the early stages of management (9). Both tests are commonly used at specialist centers, and consensus test protocols have been proposed by the working groups of the Korean Academy of Asthma, Allergy and Clinical Immunology (54,55). However, these tests are unavailable in most primary and secondary care settings (18).

Recently, there is a growing interest regarding how to apply fractionated exhaled nitric oxide (FeNO) measurement in clinical management pathways in the primary clinics in Korea, as FeNO is quick, non-invasive and easy-to-perform. One major challenge in implementing FeNO tests in clinical practice is that it is difficult to determine reference values, as various factors including ethnicity, sex, age, or atopic status may considerably affect population or subgroup ranges (56-59). The American Thoracic Society (ATS) guidelines recommend the use of cutoff points rather than reference values, based on a specific clinical setting and the research question being addressed (60).

In adult patients with chronic cough, Yi and colleagues 
found that FeNO levels $\geq 31.5 \mathrm{ppb}$ indicate more likelihood of corticosteroid-responsive cough (including cough variant asthma, eosinophilic bronchitis, or atopic cough) (61). Our subsequent meta-analyses of 13 studies (2,019 patients) found that $\mathrm{FeNO}$ has moderate diagnostic utility as a rulein test for detecting cough variant asthma (62). Summary area under the curve (AUC) was 0.87 (95\% CI, 0.83-0.89), and notably, specificity was higher and more consistent than sensitivity $(0.85,95 \%$ CI, $0.81-0.88$ and $0.72,95 \%$ CI, $0.61-0.81$, respectively) (62). The diagnostic characteristics of FeNO were consistently observed in later published studies of Japanese and Chinese patients with chronic cough $(63,64)$.

However, for detecting non-asthmatic eosinophilic bronchitis, there is only limited evidence to guide the application of $\mathrm{FeNO}$. Oh and colleagues found that the cutoff levels of $31.7 \mathrm{ppb}$ have a sensitivity of $86 \%$ and a specificity of $76 \%$ for the detection of eosinophilic bronchitis among Korean patients with non-asthmatic chronic cough (65). Our meta-analysis identified four available studies (390 patients) including the study by $\mathrm{Oh}$ et al. (65), and estimated the summary AUC as 0.81 (95\% CI, $0.77-0.84)$, sensitivity as $0.72(95 \%$ CI, 0.62-0.80), and specificity as 0.83 (95\% CI, $0.73-$ 0.90) (62). However, neither sensitivity nor specificity appears to be an advantage of the FeNO test in the detection of eosinophilic bronchitis. Relatively poor accuracy of FeNO in detecting sputum eosinophilia was similarly found in a meta-analysis of asthmatic patients by Korevaar et al. (66), in that the summary AUC was 0.74 (95\% CI, 0.70-0.78), and the sensitivity and specificity were only 0.66 (95\% CI, $0.57-0.75)$ and 0.76 (95\% CI, 0.65-0.85), respectively. The discrepancy between FeNO and sputum eosinophil counts may be attributed to different mechanisms of regulation (IL-4/IL-13 for FeNO $v s$. IL-5 for eosinophils), or to observer variability in conducting and interpreting induced sputum analyses. However, the predictability of treatment response is a clinically important outcome for a diagnostic test, and the FeNO test may be potentially useful in predicting inhaled corticosteroid (ICS) response in patients with chronic cough (67).

Despite these uncertainties, the Korean guideline committee agreed that a practical alternative test to induced sputum analyses should be introduced to clinics in daily practice, and decided to adapt the Korean patient data (65) to formulate a recommendation for the use of FeNO to predict asthma or eosinophilic bronchitis in Korean patients with chronic cough (Figure 1) (9).

\section{Natural course and optimal management of eosinophilic bronchitis}

Although eosinophilic bronchitis is a common treatable trait in chronic cough, the natural course of patients with eosinophilic bronchitis is unclear. In a case series study of Korean patients with eosinophilic bronchitis, three of four cases followed up for more than six months re-developed eosinophilic bronchitis with cough and one patient developed asthma during 18 months of follow-up (68). In a prospective cohort study of 24 patients with eosinophilic bronchitis (observed up to 48 months), sputum eosinophilia recurred in five patients (21\%) at between four and 24 months (69). Progressive forced expiratory volume in one second (FEV1) reduction $>20 \%$ was observed in three of five patients with recurrent eosinophilic bronchitis, but not in those patients without recurrent eosinophilia (69). In a retrospective cohort study of Korean patients, chronic airflow obstruction developed in five of 48 patients with eosinophilic bronchitis, and exacerbations requiring systemic corticosteroids, antibiotics, or hospitalization occurred in 15 patients (70). However, in a prospective study of Chinese patients with eosinophilic bronchitis (followed for > one year; median, 4.1 years), relapsing cases were reported in about $60 \%$ of the patients, and mild asthma developed in $5.7 \%$, whereas progressive decline in lung function was not observed (71). In a UKbased prospective study of 32 patients with eosinophilic bronchitis with available longitudinal data for more than one year, three patients (9\%) developed asthma and five patients (16\%) developed fixed airflow obstruction (72).

These observational studies are not directly comparable due to considerable methodological and clinical heterogeneities. However, host factors may affect the natural course of eosinophilic bronchitis. Smoking may play a role in development of airflow obstruction. Concomitant blood eosinophilia might also increase the risk of recurrence (69), although larger studies are warranted to confirm this hypothesis.

Optimal management for eosinophilic bronchitis is unknown, although ICS is considered the mainstay treatment. In clinical experience, cough in patients with eosinophilic bronchitis usually responds to ICS treatment within 1 or 2 months (11). However, it is unknown how long the treatment should be maintained. In a recent randomized 
open label trial of Chinese patients with cough $>3$ weeks and eosinophilic bronchitis, ICS treatment (budesonide 200 $\mu \mathrm{g}$, twice daily) significantly reduced cough visual analogue scale scores (from $5.9 \pm 2.0$ to $1.3 \pm 1.7$ ) and sputum eosinophil counts [from $7.6 \%(4.5-13.0 \%)$ to $1.0 \%(0-3.2 \%)$ ] in the one-month treatment group; however, the relapse rate was significantly associated with persistent sputum eosinophilia but was lower in the four-month treatment group than in the one-month group $(10.7 \%$ vs. $41.9 \% ; \mathrm{P}=0.007)$ (73). Given the recurrence in some patients, a biomarker-driven ICS stepping-down strategy, based on repeated measures of FeNO or eosinophil counts, may be warranted.

\section{Gastroesophageal reflux disease (GERD) and proton pump inbibitor (PPI) use}

The prevalence of GERD in Korean patients with chronic cough was mostly determined using subjective criteria (16). One study at a tertiary hospital utilizing objective 24-hour esophageal $\mathrm{pH}$ monitoring found that only $1.7 \%$ of patients with chronic cough had acid-reflux-associated cough (74). Recent studies suggest that GERD is becoming more prevalent in East Asian populations (75-77), suggesting that the burden from GERD-associated cough may continue to increase.

Pathophysiology and management of GERDassociated cough are still controversial. It has been recently recognized that acid reflux may have a minor role in chronic cough (78). Recent guidelines recommend against the routine use of acid suppression therapy in chronic cough patients, in the absence of symptoms or signs suggestive of acid reflux $(9,11,79)$. In a clinical trial of Korean patients with chronic cough, PPI treatment was associated with significant improvement in cough-specific QoL, as compared to placebo. However, these results warrant validation, because the baseline comparability was not met between different treatment groups (80).

There are no formal published data, but a considerable number of patients coming to our cough clinics have taken PPIs in the absence of clinical history or objective tests suggesting acid reflux. In observational studies, the use of PPIs is associated with risks of elderly prone diseases like pneumonia, Clostridium difficile infection, osteoporosis, bone fracture, or dementia $(81,82)$; although the degree of associations is mostly modest, the summed impact may be substantial given the high number of patients exposed to PPIs.

Recent studies suggest potential relevance of non-acid reflux in chronic cough (83-85). In a retrospective cohort study of Korean patients with chronic cough, baseline symptoms of non-acid reflux, such as coughing with eating or cough with certain foods, were associated with the risk of cough persistence at four years after systematic assessment at a tertiary clinic (86). In an open label, single arm intervention study in China, administration of baclofen as an add-on yielded a favorable response in $36.9 \%$ of patients with GERD-associated cough who were refractory to antacid therapy (87). However, causal relationships of non-acid reflux are not confirmed, as there are no published placebo-controlled RCTs examining pro-motility drugs in chronic cough patients (11).

\section{Infection-associated chronic cough}

In the literature published from Asian countries, infectious causes are still considered important in patients with chronic cough (13). The incidence of pulmonary tuberculosis is consistently decreasing, but the statistics report higher rates of incidence and mortality of tuberculosis in Korea among the Organisation for Economic Co-operation and Development (OECD) countries (88). Therefore, it is recommended to consider pulmonary tuberculosis as a differential diagnosis in Korean patients with cough lasting more than two to three weeks (15).

Pulmonary paragonimiasis is considered as a cause of persistent cough in some endemic areas of Southeast Asian countries (13). However, there are some cases reported in Korea; in a retrospective study of 36 Korean patients diagnosed with pulmonary paragonimiasis between 1994 and 2004, cough was the second common symptom (47\%) (89). Paragonimiasis is frequently associated with endemicity and a dietary habit of eating raw crab, but may need to be suspected in immigrants or overseas travelers with chronic cough and highly suggestive history and abnormal chest radiographs $(90,91)$.

There are studies investigating the incidence of pertussis in Korean adolescents or adults with bothersome cough (92-95). However, only one study (95) included subjects with cough lasting up to 12 weeks, in which no one with chronic cough ( $\geq$ eight weeks) reported positive polymerase chain reaction assay results for Bordetella pertussis. Given the concern about potential under-estimation of pertussis, more active surveillance might be needed particularly in Korean elderly with cough, due to waning effects of pertussis vaccination and increasing incidence in adults aged older than 70 years as reported by the Korea Centers for Disease 
Control and Prevention (96).

\section{Unexplained or refractory chronic cough}

Unexplained or refractory chronic cough is a globally important target for novel drug development, due to its high impact on QoL and the lack of safe and effective treatments. Patients with chronic refractory cough experience unwanted social attention, personal isolation, depression, and feelings of helplessness $(18,97)$. There is no comprehensive estimation on their healthcare utilization, but clinical experience suggests that these patients frequently undergo unnecessary investigations or treatments that are potentially harmful, such as oral corticosteroids, without adding any clinical benefits to controlling the cough. Currently available drugs have been empirically identified from centrally-acting drugs for pain or neuropathic conditions, such as opiates, gabapentin, or pregabalin (98-100); but they are only effective in a subset of patients with chronic refractory cough, and their frequent, sometimes serious, side effects limit their widespread use. In this regard, the success of P2X3 antagonists or other neuromodulators (such as neurokinin-1 receptor antagonists) in clinical trials (101-103) will be an important milestone.

The incidence of unexplained or refractory chronic cough has not been formally reported in Korean populations, although it is presumed $10-20 \%$ of patients with chronic cough attending specialist clinics (48). They are mostly non-smoking elderly women, characterized by hypersensitivity in cough reflex and abnormal laryngeal sensation (48). Approximately half of these patients have a cough that has persisted for more than five years $(18,48)$. At present, codeine is considered as the best available drug for these patients in Korea (9). Speech language therapy is recommended in the recent Korean guidelines (9), but the service should be provided by experienced professionals; however, the pool of speech therapists qualified for this type of therapy is lacking. The burden of unexplained or refractory chronic cough has not been estimated yet. Healthcare utilization and future risk of adverse health outcomes should be also examined.

\section{Role distributions between primary and referral clinics in the management of chronic cough}

Korea has a universal health coverage system, and ensures easy access to referral clinics (104). The simple referral system helps patients visit specialist clinics or tertiary hospitals without a long wait. In 2017, the annual number of doctor consultations per person was 16.6 in Korea, which is higher by far than the OECD average (6.8) (https://www.oecd.org/health/health-data.htm). This easier physician and treatment access may have attributed to a relatively short duration of cough among patients visiting specialist clinics in Korea (48). It is also presumed that there are considerable overlaps in the cough patient populations and clinical roles between primary clinics and referral centers in Korea.

In the recent Korean guidelines for chronic cough management (9), the concept of non-specific chronic cough was introduced, which indicates chronic cough in the absence of any symptoms, signs, history, or laboratory findings indicating a specific diagnosis for (specific cough pointers), such as use of angiotensin-converting enzyme inhibitors, current smoking, any evident symptoms indicating a specific diagnosis (fever, blood-tinged sputum, wheezing, dyspnea, rhinorrhea, nasal obstruction, or heartburn), abnormal physical findings (wheezing or crackles on auscultation), or abnormal findings on chest $\mathrm{X}$-rays and/or spirometry. Then, three initial roles were assigned (but not exclusively) to primary and secondary cares: (I) screening of specific cough, based on history, physical examination, chest $\mathrm{X}$-rays, or spirometry; (II) short-term empirical trials with H1RA or ICS in patients with non-specific chronic cough; and (III) FeNO tests to identify patients responsive to ICS. Referral to specialist center is recommended if a patient needs further diagnostic tests or management, or if cough is refractory to empirical trials (9) (Figure 1). However, studies are warranted to characterize patients with chronic cough in the community, and to validate the roles of primary care in the management of chronic cough Korea.

\section{Knowledge gaps and future research directions}

This section summarizes future research directions, based on the current status and knowledge gaps as discussed above (Figure 2).

* The burden of chronic cough in the elderly is expected to increase substantially in the near future. Further studies are warranted to reveal the mechanisms of the aging-related increase and to develop precise prevention and management strategies for cough in this population.

* Effects of air pollution on chronic cough problems should be investigated. Given the protective nature 


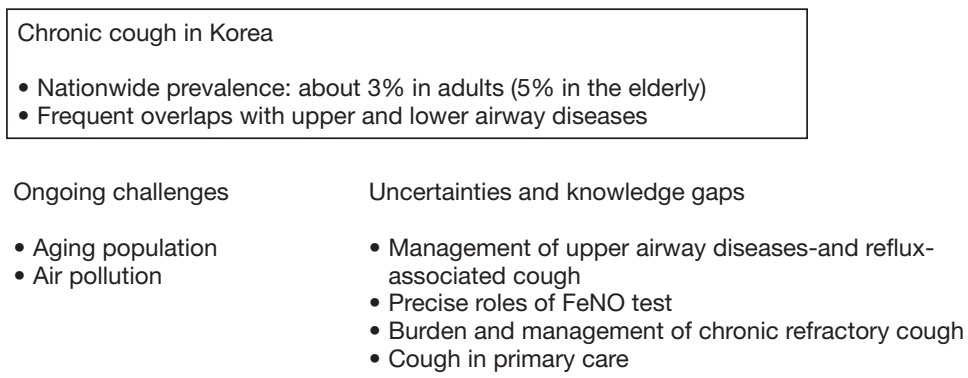

Figure 2 Summary of current challenges, and major uncertainties and knowledge gaps in the management of chronic cough in Korea.

of cough, the true impact on chronic cough warrants longitudinal investigation, particularly for its longterm remnant effects.

* Clinical strategy should be revisited, particularly with respect to the efficacy and utility of diagnostic tests and therapeutic drugs for upper airway diseases in patients with chronic cough.

* FeNO is being incorporated into the clinical practice of chronic cough in Korean patients. However, further clinical evidence is required to confirm its use in the diagnostic pathways and longitudinal follow-ups of cough patients.

* Reflux-associated cough warrants further attention, given the recent increase of GERD in Asian populations. Meanwhile, there is a widespread use of PPI for patients with cough, which is unlikely to help patients in the absence of acid reflux.

* The disease burden of chronic cough should be measured.

* Cough patients in the community need to be characterized. Studies are also warranted to validate the roles of primary care in the management of chronic cough.

\section{Conclusions}

Chronic cough is a globally common condition, but also affects about $3 \%$ of the general adult population in Korea with a significant impact on QoL. Aging population and air pollution are major challenges from epidemiological perspectives. Clinically, upper and lower airway diseasesrhinitis/rhinosinusitis and cough variant asthma/eosinophilic bronchitis-are considered to be major comorbid conditions in Korean adults with chronic cough, which formed the basis in formulating clinical practice guidelines. However, there are uncertainties and unmet needs in how to assess and manage these conditions more precisely and more effectively. GERD- and infection-associated cough problems are additional concerns. Further studies are warranted to refine our clinical strategy and reduce the disease burden.

\section{Acknowledgments}

Funding: None.

\section{Footnote}

Provenance and Peer Review: This article was commissioned by the Guest Editor (Kefang Lai) for the series "3rd International Cough Conference" published in fournal of Thoracic Disease. The article has undergone external peer review.

Conflicts of Interest: Both authors have completed the ICMJE uniform disclosure form (available at http:// dx.doi.org/10.21037/jtd-2020-icc-004). The series "3rd International Cough Conference" was commissioned by the editorial office without any funding or sponsorship. WJS serves as an unpaid editorial board member of fournal of Thoracic Disease. The author has no other conflicts of interest to declare.

Ethical Statement: The authors are accountable for all aspects of the work in ensuring that questions related to the accuracy or integrity of any part of the work are appropriately investigated and resolved.

Open Access Statement: This is an Open Access article distributed in accordance with the Creative Commons Attribution-NonCommercial-NoDerivs 4.0 International License (CC BY-NC-ND 4.0), which permits the non- 
commercial replication and distribution of the article with the strict proviso that no changes or edits are made and the original work is properly cited (including links to both the formal publication through the relevant DOI and the license). See: https://creativecommons.org/licenses/by-nc-nd/4.0/.

\section{References}

1. Dicpinigaitis PV. Clinical perspective-cough: an unmet need. Curr Opin Pharmacol 2015;22:24-8.

2. Cho SH, Lin HC, Ghoshal AG, et al. Respiratory disease in the Asia-Pacific region: Cough as a key symptom. Allergy Asthma Proc 2016;37:131-40.

3. Irwin RS, Corrao WM, Pratter MR. Chronic persistent cough in the adult: the spectrum and frequency of causes and successful outcome of specific therapy. Am Rev Respir Dis 1981;123:413-7.

4. Morice AH, McGarvey L, Pavord I. Recommendations for the management of cough in adults. Thorax 2006;61:11-24.

5. Committee for the Japanese Respiratory Society Guidelines for Management of C, Kohno S, Ishida $\mathrm{T}$, et al. The Japanese Respiratory Society guidelines for management of cough. Respirology 2006;11 Suppl 4:S135-86.

6. Gibson PG, Chang AB, Glasgow NJ, et al. CICADA: Cough in Children and Adults: Diagnosis and Assessment. Australian cough guidelines summary statement. Med J Aust 2010;192:265-71.

7. Irwin RS, French CL, Chang AB, et al. Classification of cough as a symptom in adults and management algorithms: CHEST guideline and expert panel report. Chest 2018;153:196-209.

8. Lai K, Shen H, Zhou X, et al. Clinical Practice Guidelines for Diagnosis and Management of Cough-Chinese Thoracic Society (CTS) Asthma Consortium. J Thorac Dis 2018;10:6314-51.

9. Song DJ, Song WJ, Kwon JW, et al. KAAACI EvidenceBased Clinical Practice Guidelines for Chronic Cough in Adults and Children in Korea. Allergy Asthma Immunol Res 2018;10:591-613.

10. Kardos P, Dinh QT, Fuchs KH, et al. Guidelines of the German Respiratory Society for Diagnosis and Treatment of Adults Suffering from Acute, Subacute and Chronic Cough. Pneumologie 2019;73:143-80.

11. Morice AH, Millqvist E, Bieksiene K, et al. ERS guidelines on the diagnosis and treatment of chronic cough in adults and children. Eur Respir J 2020;55:1901136.

12. Song WJ, Chang YS, Faruqi S, et al. The global epidemiology of chronic cough in adults: a systematic review and meta-analysis. Eur Respir J 2015;45:1479-81.

13. Song WJ, Faruqi S, Klaewsongkram J, et al. Chronic cough: an Asian perspective. Part 1: Epidemiology. Asia Pac Allergy 2015;5:136-44.

14. Lai K, Long L, Yi F, et al. Age and Sex Distribution of Chinese Chronic Cough Patients and Their Relationship With Capsaicin Cough Sensitivity. Allergy Asthma Immunol Res 2019;11:871-84.

15. Rhee CK, Jung JY, Lee SW, et al. The Korean Cough Guideline: Recommendation and Summary Statement. Tuberc Respir Dis (Seoul) 2016;79:14-21.

16. Kang SY, Kim GW, Song WJ, et al. Chronic cough in Korean adults: a literature review on common comorbidity. Asia Pac Allergy 2016;6:198-206.

17. Kim SH, Song WJ, Kwon JW, et al. Allergists' Perceptions and Practices on the Management of Chronic Cough in Korea: A Questionnaire Survey. Korean J Asthma Allergy Clin Immunol 2012;032:239253.

18. Kang SY, Won HK, Lee SM, et al. Impact of Cough and Unmet Needs in Chronic Cough: A Survey of Patients in Korea. Lung 2019;197:635-9.

19. Morice AH, Millqvist E, Belvisi MG, et al. Expert opinion on the cough hypersensitivity syndrome in respiratory medicine. Eur Respir J 2014;44:1132-48.

20. Mazzone SB, Chung KF, McGarvey L. The heterogeneity of chronic cough: a case for endotypes of cough hypersensitivity. Lancet Respir Med 2018;6:636-46.

21. Song WJ, Chung KF. Exploring the clinical relevance of cough hypersensitivity syndrome. Expert Rev Respir Med 2020;14:275-84.

22. Park HK, Oh SY, Kim TB, et al. Association of genetic variations in neurokinin-2 receptor with enhanced cough sensitivity to capsaicin in chronic cough. Thorax 2006;61:1070-5.

23. Smit LA, Kogevinas M, Anto JM, et al. Transient receptor potential genes, smoking, occupational exposures and cough in adults. Respir Res 2012;13:26.

24. Won HK, Lee JH, An J, et al. Impact of Chronic Cough on Health-related Quality of Life in Korean Adult General Populations: The Korean National Health and Nutrition Examination Survey 2010-2016. Allergy Asthma Immunol Res 2020;12:964-79.

25. Kang MG, Song WJ, Kim HJ, et al. Point prevalence and epidemiological characteristics of chronic cough in the general adult population: The Korean National Health and Nutrition Examination Survey 2010-2012. Medicine (Baltimore) 2017;96:e6486. 
26. Shin C, Lee S, Abbott RD, et al. Respiratory symptoms and undiagnosed airflow obstruction in middle-aged adults: the Korean Health and Genome Study. Chest 2004;126:1234-40.

27. Song WJ, Morice AH, Kim MH, et al. Cough in the elderly population: relationships with multiple comorbidity. PLoS One 2013;8:e78081.

28. Song WJ, Won HK, An J, et al. Chronic cough in the elderly. Pulm Pharmacol Ther 2019;56:63-8.

29. Song WJ, Chang YS. Respiratory allergies in the elderly: findings from the Korean Longitudinal Study on Health and Aging phase I study (2005-2006). Asia Pac Allergy 2017;7:185-92.

30. Won HK, Yoon SJ, Song WJ. The double-sidedness of cough in the elderly. Respir Physiol Neurobiol 2018;257:65-9.

31. Mcgarvey L, Morice A, Way N, et al. Prevalence of chronic cough, patient characteristics and health outcomes among UK adults. Madrid, Spain: Eur Respiratory Soc, 2019.

32. Song WJ, Wong GWK. Changing trends and challenges in the management of asthma in Asia. J Allergy Clin Immunol 2017;140:1272-4.

33. Jo EJ, Song WJ. Environmental triggers for chronic cough. Asia Pac Allergy 2019;9:e16.

34. Fang Z, Huang C, Zhang JJ, et al. Traffic-related air pollution induces non-allergic eosinophilic airway inflammation and cough hypersensitivity in guinea-pigs. Clin Exp Allergy 2019;49:366-77.

35. Lv H, Yue J, Chen Z, et al. Effect of transient receptor potential vanilloid-1 on cough hypersensitivity induced by particulate matter 2.5. Life Sci 2016;151:157-66.

36. Nakao M, Ishihara Y, Kim CH, et al. The Impact of Air Pollution, Including Asian Sand Dust, on Respiratory Symptoms and Health-related Quality of Life in Outpatients With Chronic Respiratory Disease in Korea: A Panel Study. J Prev Med Public Health 2018;51:130-9.

37. Eom SY, Choi J, Bae S, et al. Health effects of environmental pollution in population living near industrial complex areas in Korea. Environ Health Toxicol 2018;33:e2018004.

38. Morice AH, Jakes AD, Faruqi S, et al. A worldwide survey of chronic cough: a manifestation of enhanced somatosensory response. Eur Respir J 2014;44:1149-55.

39. French CT, Fletcher KE, Irwin RS. Gender differences in health-related quality of life in patients complaining of chronic cough. Chest 2004;125:482-8.

40. Rostami-Hodjegan A, Abdul-Manap R, Wright CE, et al. The placebo response to citric acid-induced cough: pharmacodynamics and gender differences. Pulm Pharmacol Ther 2001;14:315-9.

41. Kelsall A, Decalmer S, McGuinness K, et al. Sex differences and predictors of objective cough frequency in chronic cough. Thorax 2009;64:393-8.

42. Fujimura M, Sakamoto S, Kamio Y, et al. Sex difference in the inhaled tartaric acid cough threshold in non-atopic healthy subjects. Thorax 1990;45:633-4.

43. Dicpinigaitis PV, Rauf K. The influence of gender on cough reflex sensitivity. Chest 1998;113:1319-21.

44. Song WJ, Kim JY, Jo EJ, et al. Capsaicin cough sensitivity is related to the older female predominant feature in chronic cough patients. Allergy Asthma Immunol Res 2014;6:401-8.

45. Kavalcikova-Bogdanova N, Kovacikova L, Buday T, et al. Sensitivity of airway cough-related afferents is influenced by female sex hormones. Respir Physiol Neurobiol 2018;257:12-7.

46. Kavalcikova-Bogdanova N, Buday T, Plevkova J, et al. Chronic Cough as a Female Gender Issue. Adv Exp Med Biol 2016;905:69-78.

47. Dicpinigaitis PV, Allusson VR, Baldanti A, et al. Ethnic and gender differences in cough reflex sensitivity. Respiration 2001;68:480-2.

48. Won HK, Kang SY, Kang Y, et al. Cough-Related Laryngeal Sensations and Triggers in Adults With Chronic Cough: Symptom Profile and Impact. Allergy Asthma Immunol Res 2019;11:622-31.

49. Church MK, Maurer M, Simons F, et al. Risk of firstgeneration $\mathrm{H} 1$-antihistamines: a GA2LEN position paper. Allergy 2010;65:459-66.

50. Lee SE, Lee JH, Kim HJ, et al. Inhaled Corticosteroids and Placebo Treatment Effects in Adult Patients With Cough: A Systematic Review and Meta-analysis. Allergy Asthma Immunol Res 2019;11:856-70.

51. Plevkova J, Song WJ. Chronic cough in subjects with upper airway diseases - analysis of mechanisms and clinical applications. Asia Pac Allergy 2013;3:127-35.

52. O'Hara J, Jones N. " Post-nasal drip syndrome": most patients with purulent nasal secretions do not complain of chronic cough. Rhinology 2006;44:270-3.

53. Pratter MR, Bartter T, Lotano R. The role of sinus imaging in the treatment of chronic cough in adults. Chest 1999;116:1287-91.

54. $\mathrm{Kim}$ MH, Kim MY, Lim KH, et al. KAAACI Standardization Committee report on the procedure and application of induced sputum examination. Allergy 
Asthma Respir Dis 2017;5:307-11.

55. Lim KH, Kim MH, Yang MS, et al. The KAAACI Standardization Committee Report on the procedure and application of the bronchial provocation tests. Allergy Asthma Respir Dis 2018;6:14-25.

56. Kwon JW, Song WJ, Kim MH, et al. The KAAACI Standardization Committee Report on the procedure and application of fractional exhaled nitric oxide measurement. Allergy Asthma Respir Dis 2017;5:185-92.

57. Jo EJ, Song WJ, Kim TW, et al. Reference ranges and determinant factors for exhaled nitric oxide in a healthy korean elderly population. Allergy Asthma Immunol Res 2014;6:504-10.

58. Kim SH, Kim TH, Sohn JW, et al. Reference values and determinants of exhaled nitric oxide in healthy Korean adults. J Asthma 2010;47:563-7.

59. Song WJ, Kwon JW, Kim EJ, et al. Clinical application of exhaled nitric oxide measurements in a korean population. Allergy Asthma Immunol Res 2015;7:3-13.

60. Dweik RA, Boggs PB, Erzurum SC, et al. An official ATS clinical practice guideline: interpretation of exhaled nitric oxide levels (FENO) for clinical applications. Am J Respir Crit Care Med 2011;184:602-15.

61. Yi F, Chen R, Luo W, et al. Validity of fractional exhaled nitric oxide in diagnosis of corticosteroid-responsive cough. Chest 2016;149:1042-51.

62. Song WJ, Kim HJ, Shim JS, et al. Diagnostic accuracy of fractional exhaled nitric oxide measurement in predicting cough-variant asthma and eosinophilic bronchitis in adults with chronic cough: A systematic review and meta-analysis. J Allergy Clin Immunol 2017;140:701-9.

63. Asano T, Takemura M, Fukumitsu K, et al. Diagnostic utility of fractional exhaled nitric oxide in prolonged and chronic cough according to atopic status. Allergol Int 2017;66:344-50.

64. Zhou J, Zhao X, Zhang X, et al. Values of fractional exhaled nitric oxide for cough-variant asthma in children with chronic cough. J Thorac Dis 2018;10:6616-23.

65. Oh MJ, Lee JY, Lee BJ, et al. Exhaled nitric oxide measurement is useful for the exclusion of nonasthmatic eosinophilic bronchitis in patients with chronic cough. Chest 2008;134:990-5.

66. Korevaar DA, Westerhof GA, Wang J, et al. Diagnostic accuracy of minimally invasive markers for detection of airway eosinophilia in asthma: a systematic review and meta-analysis. Lancet Respir Med 2015;3:290-300.

67. Chaudhuri R, McMahon AD, Thomson LJ, et al. Effect of inhaled corticosteroids on symptom severity and sputum mediator levels in chronic persistent cough. J Allergy Clin Immunol 2004;113:1063-70.

68. Joo JH, Park SJ, Park SW, et al. Clinical features of eosinophilic bronchitis. Korean J Intern Med 2002;17:31-7.

69. Park SW, Lee YM, Jang AS, et al. Development of chronic airway obstruction in patients with eosinophilic bronchitis: a prospective follow-up study. Chest 2004;125:1998-2004.

70. Cho J, Choi SM, Lee J, et al. Clinical outcome of eosinophilic airway inflammation in chronic airway diseases including nonasthmatic eosinophilic bronchitis. Sci Rep 2018;8:146.

71. Lai K, Liu B, Xu D, et al. Will nonasthmatic eosinophilic bronchitis develop into chronic airway obstruction?: a prospective, observational study. Chest 2015;148:887-94.

72. Berry MA, Hargadon B, McKenna S, et al. Observational study of the natural history of eosinophilic bronchitis. Clin Exp Allergy 2005;35:598-601.

73. Zhan W, Tang J, Chen X, et al. Duration of treatment with inhaled corticosteroids in nonasthmatic eosinophilic bronchitis: a randomized open label trial. Ther Adv Respir Dis 2019;13:1753466619891520.

74. Kwon NH, Lee BJ, Choi DC. Chronic cough of unknown causes and gastroesophageal reflux disease: the incidence and treatment response. Korean J Med 2005;69:528.

75. Niimi A. Cough associated with gastro-oesophageal reflux disease (GORD): Japanese experience. Pulm Pharmacol Ther 2017;47:59-65.

76. Ding H, Xu X, Wen S, et al. Changing etiological frequency of chronic cough in a tertiary hospital in Shanghai, China. J Thorac Dis 2019;11:3482-9.

77. Long L, Lai K. Characteristics of Chinese chronic cough patients. Pulm Pharmacol Ther 2019;57:101811.

78. Kahrilas PJ, Howden CW, Hughes N, et al. Response of chronic cough to acid-suppressive therapy in patients with gastroesophageal reflux disease. Chest 2013;143:605-12.

79. Kahrilas PJ, Altman KW, Chang AB, et al. Chronic cough due to gastroesophageal reflux in adults: CHEST guideline and expert panel report. Chest 2016;150:1341-60.

80. Park HJ, Park YM, Kim JH, et al. Effectiveness of proton pump inhibitor in unexplained chronic cough. PLoS One 2017;12:e0185397.

81. Giuliano C, Wilhelm SM, Kale-Pradhan PB. Are proton pump inhibitors associated with the development of community-acquired pneumonia? A meta-analysis. Expert Rev Clin Pharmacol 2012;5:337-44.

82. Yadlapati R, Kahrilas PJ. The "dangers" of chronic proton pump inhibitor use. J Allergy Clin Immunol 
2018;141:79-81.

83. Smith JA, Decalmer S, Kelsall A, et al. Acoustic coughreflux associations in chronic cough: potential triggers and mechanisms. Gastroenterology 2010;139:754-62.

84. Herregods TVK, Pauwels A, Jafari J, et al. Determinants of reflux-induced chronic cough. Gut 2017;66:2057-62.

85. Burke JM, Jackson W, Morice AH. The role of high resolution oesophageal manometry in occult respiratory symptoms. Respir Med 2018;138:47-9.

86. Kang SY, Song WJ, Won HK, et al. Cough persistence in adults with chronic cough: a 4-year retrospective cohort study. Allergol Int 2020;S1323-8930(20)30049-6.

87. Xu X, Lv H, Yu L, et al. A stepwise protocol for the treatment of refractory gastroesophageal reflux-induced chronic cough. J Thorac Dis 2016;8:178-85.

88. Cho KS. Tuberculosis control in the Republic of Korea. Epidemiol Health 2018;40:e2018036.

89. Jeon K, Koh WJ, Kim H, et al. Clinical features of recently diagnosed pulmonary paragonimiasis in Korea. Chest 2005;128:1423-30.

90. Yoshida A, Doanh PN, Maruyama H. Paragonimus and paragonimiasis in Asia: An update. Acta Trop 2019;199:105074.

91. Kim EM, Kim JL, Choi SI, et al. Infection status of freshwater crabs and crayfish with metacercariae of Paragonimus westermani in Korea. Korean J Parasitol 2009;47:425-6.

92. Park S, Lee MG, Lee KH, et al. A Multicenter Study of Pertussis Infection in Adults with Coughing in Korea: PCR-Based Study. Tuberc Respir Dis (Seoul) 2012;73:266-72.

93. Park S, Lee SH, Seo KH, et al. Epidemiological aspects of pertussis among adults and adolescents in a Korean outpatient setting: a multicenter, PCR-based study. J Korean Med Sci 2014;29:1232-9.

94. Lee SY, Han SB, Kang JH, et al. Pertussis Prevalence in Korean Adolescents and Adults with Persistent Cough. J

Cite this article as: Lee JH, Song WJ. Perspectives on chronic cough in Korea. J Thorac Dis 2020;12(9):5194-5206. doi: 10.21037/jtd-2020-icc-004
Korean Med Sci 2015;30:988-90.

95. Park WB, Park SW, Kim HB, et al. Pertussis in adults with persistent cough in South Korea. Eur J Clin Microbiol Infect Dis 2005;24:156-8.

96. Choe YJ, Kim JW, Park YJ, et al. Burden of pertussis is underestimated in South Korea: a result from an active sentinel surveillance system. Jpn J Infect Dis 2014;67:230-2.

97. Hulme K, Dogan S, Parker SM, et al. 'Chronic cough, cause unknown': A qualitative study of patient perspectives of chronic refractory cough. J Health Psychol 2019;24:70716.

98. Morice AH, Menon MS, Mulrennan SA, et al. Opiate therapy in chronic cough. Am J Respir Crit Care Med 2007;175:312-5.

99. Ryan NM, Birring SS, Gibson PG. Gabapentin for refractory chronic cough: a randomised, double-blind, placebo-controlled trial. Lancet 2012;380:1583-9.

100. Vertigan AE, Kapela SL, Ryan NM, et al. Pregabalin and Speech Pathology Combination Therapy for Refractory Chronic Cough: A Randomized Controlled Trial. Chest 2016;149:639-48.

101.Abdulqawi R, Dockry R, Holt K, et al. P2X3 receptor antagonist (AF-219) in refractory chronic cough: a randomised, double-blind, placebo-controlled phase 2 study. Lancet 2015;385:1198-205.

102. Smith JA, Kitt MM, Morice AH, et al. Gefapixant, a P2X3 receptor antagonist, for the treatment of refractory or unexplained chronic cough: a randomised, double-blind, controlled, parallel-group, phase $2 \mathrm{~b}$ trial. Lancet Respir Med 2020;8:775-85.

103. Smith J, Allman D, Badri H, et al. The neurokinin-1 receptor antagonist orvepitant is a novel antitussive therapy for chronic refractory cough: results from a phase 2 pilot study (VOLCANO-1). Chest 2020;157:111-8.

104. Song YJ. The South Korean Health Care System. Japan Medical Association Journal 2009;52:106-209. 